\title{
Health and Nutritional Status of Young Foster Children Attending a Diarrhea Treatment Hospital in Bangladesh ${ }^{*}$
}

\author{
Durdana Akhter ${ }^{1}$, Sumon Kumar Das ${ }^{2 \#}$, Mohammod Jobayer Chisti ${ }^{2}$, Gazi Imran ${ }^{3}$, \\ Fahmida Dil Farzana ${ }^{2}$, Shahnawaz Ahmed ${ }^{2}$, Farzana Ferdous ${ }^{2}$, Mohammad Abdul Malek ${ }^{2}$, \\ Abu Syed Golam Faruque ${ }^{2}$ \\ ${ }^{1}$ Centre for Vaccine Sciences (CVS), International Centre for Diarrhoeal Disease Research, Bangladesh (icddr,b), Dhaka, Bangladesh; \\ ${ }^{2}$ Centre for Nutrition and Food Security (CNFS), icddr,b, Dhaka, Bangladesh; ${ }^{3}$ Dhaka Shishu (Children's) Hospital, Dhaka, Bangla- \\ desh. \\ Email: durdanabd@yahoo.com, ${ }^{\#}$ sumon@icddrb.org, chisti@icddrb.org, litons.imran@gmail.com, fahmidaf@icddrb.org, \\ shahnawz@icddrb.org, farzanaf@icddrb.org,mamalek@icddrb.org,gfaruque@icddrb.org
}

Received May $5^{\text {th }}, 2013$; revised June $5^{\text {th }}, 2013$; accepted June $14^{\text {th }}, 2013$

Copyright (C) 2013 Durdana Akhter et al. This is an open access article distributed under the Creative Commons Attribution License, which permits unrestricted use, distribution, and reproduction in any medium, provided the original work is properly cited.

\begin{abstract}
There is scarcity of evidence-based information about socio-demographic as well as ailment factors associated with foster children in Bangladesh. Thus the aim of the present study was to determine the socio-economic, health and nutritional status of young foster children in urban Dhaka. A total of $208(1 \% ; n=208 / 28,948)$ under-5 foster children were enrolled in the Diarrheal Disease Surveillance System of icddr,b between 1993-2012. Randomly selected under-5 children $(n=624)$ with a ratio of $1: 3$ were extracted and constituted as comparison group. Forty-three percent $(n=90)$ foster children were male. Lack of formal schooling of mother was higher among foster children compared to non-foster children $(52 \%$ vs. $35 \% ; p<0.001)$. Higher proportion of foster children suffered from some or severe dehydration $(60 \%$ vs. $47 \% ; \mathrm{p}=0.001)$ and often received intravenous saline $(12 \%$ vs. $5 \% ; \mathrm{p}=0.002)$ in comparison to non-foster children. Significantly lower proportion of foster children had rotavirus diarrhea ( $26 \%$ vs. $43 \%$; $p<0.001)$. In multivariate analysis, foster children were 2 times (95\% CI: 1.31 - 4.32) more likely to be stunted and 194 times (95\% CI: 82.25 457.76) more likely to be non-breastfed. Infants aged 6 - 11 months were 8 times (95\% CI: $3.70-15.50)$ more likely to be foster compared to older children and probability of fostering was 7 times (95\% CI: $3.96-13.33$ ) higher among mothers with a median age of 25 years. The findings of our study clearly demonstrate the existing health and nutritional problems of foster children. Therefore, appropriate health and nutrition interventions are critical for foster children in Bangladesh.
\end{abstract}

Keywords: Bangladesh; Diarrhea; Foster Children; Malnutrition

\section{Introduction}

Since the progressive strengthening of mankind, people accommodated "fostering" (providing parental care and nurture to children not related through legal or blood ties) to further sanctify their bonding for survival. Different ethnicity adopted different perspectives on fostering based on their financial or social conditions and physical and mental health capacity [1-6]. In developing countries including Bangladesh, newborns or infants are usually

\footnotetext{
${ }^{*}$ There is no potent conflict of interest to declare. All authors confirm that there is no professional affiliation, financial agreement or other involvement with any company whose product figures prominently in the submitted manuscript.

${ }^{\#}$ Corresponding author.
}

being fostered. Formal fostering is well recognized in Bangladesh but due to lack of cognizance, foster parents are encouraged to perform informal fostering except in few orphanages where fostering used to be maintained by non-government organizations (NGOs) or by religious groups [7].

A good number of studies conducted in recent past revealed that, children in foster care may experience physical and sexual abuse coupled with social, emotional, and medical negligence [8-11]. As a result, they often become emotionally handicapped and face a number of behavioral problems including developmental delay [1214]. In affluent countries like the United States, foster care placements have been increased rapidly [7] due to 
multiple factors such as negligence, parental incapability, physical abuse, abandonment, disruptive child behavior, sexual abuse and lack of fulfillment of a child's special needs $[15,16]$. However, due to lack of proper attention and care, foster children frequently suffer from a number of ailments including poor nutrition hampering their growth, making them vulnerable to infectious diseases, and thus, requiring often hospitalization [17-19].

The dynamics of fostering children may differ in Bangladesh in comparison to developed countries because of social, cultural, and economic differences [7]. In Bangladesh, children who were fostered usually born in socially or financially disadvantaged families. The male partner of infertile couples is often pressurized by their family members to marry again or to foster a child. However, considering the fact that there is no evidence based information about the characteristics of foster children in Bangladesh, it is imperative to assess the socio-economic, health and nutritional status of foster children and share this information with policy planners for potential formulation of appropriate strategies to address health care needs of foster children.

\section{Materials and Methods}

\subsection{Study Population and Site}

The study was conducted at the Dhaka hospital of International Centre for Diarrhoeal Disease Research, Bangladesh (icddr,b). This hospital provides care and treatment to over 140,000 diarrhea patients, with or without associated health problems, each year. It also conducts research on enteric and other common infectious diseases and malnutrition, and provides training on case management and research methodology. Under-five children constitute about $60 \%$ of the total patients, and vast majority of the patients come from the poor socio-economic background of urban and peri-urban Dhaka, the capital of Bangladesh. A Diarrheal Disease Surveillance System (DDSS) was established in 1979, which systematically samples patients - 4\% of all patients from 1979 through 1995 , followed by $2 \%$ of all the patients since 1996 . The DDSS currently collects information on clinical, epidemiological and demographic characteristics, feeding practices, particularly of infants and young children, and drug and fluid therapy use at home for every 50th patient, irrespective of age, sex, disease severity or socioeconomic status through an administered structured questionnaire. Extensive microbiological investigations of fecal samples (culture, Enzyme-linked immunosorbent assay and microscopy) are routinely performed to identify diarrheal pathogens. For this retrospective analysis, we studied children of either sex, aged $<5$ years attending at Dhaka Hospital during 1993 to 2012. The study was conducted to assess the health and nutritional status of young foster children presenting to Dhaka Hospital of icddr,b.

\subsection{Sample Framing}

During the study period, a total of 28,948 under- 5 children with diarrhea were enrolled in the DDSS. Of them, $208(1 \%)$ children were identified as foster children and constituted as cases. On the other hand, randomly selected under-5 children $(n=624)$ with a ratio of $1: 3$ were extracted from the rest of the children and constituted the comparison group. Excess sample were pooled to increase the power of the study.

\subsection{Specimen Collection and Laboratory Procedure}

All patients who provided consent, a single fresh, whole stool specimen (at least $3 \mathrm{ml}$ or grams) was collected from them and sent to the Clinical Microbiological Laboratory of icddr,b for routine screening of common enteric pathogens such as Vibrio cholerae [20], Shigella spp. [20], Salmonella [20], and rotavirus [21] applying standard laboratory methods.

\subsection{Data Analysis}

Data entry and subsequent analyses were done by using SPSS (version 15.2), and Epi Info (version 6.0, USD, Stone Mountain, GA, USA). Differences in the proportions were compared by the Chi-square test. A probability of less than 0.05 was considered statistically significant. Strength of association was determined by estimating odds ratios (OR) and their $95 \%$ confidence intervals $(95 \% \mathrm{CI})$. All characteristics were analyzed in a $2 / 2$ table model (independent variables), and those significantly associated with foster children (dependent variable) were examined by backward stepwise logistic regression analysis after adjusting for the covariates (all variables significantly associated with foster children in the univariate analyses).

\subsection{Ethical Statement}

DDSS of icddr,b is a routine ongoing activity of the Dhaka Hospital which has been approved by the Research Review Committee (RRC) and Ethical Review Committee (ERC) of icddr,b. Before enrollment, verbal consent was taken from the caregivers or guardians of the patients. The information was stored in the hospital database and used for conducting researches. The DDSS of icddr,b is a scheduled activity on the hospital patients, and used to be performed after taking verbal consent from the parents or guardians of the patients following the hospital policy. Parents or guardians were assured about the non-disclosure of information collected from 
them, and were also informed about the use of data for analysis and using the results for improving patient care activities as well as publications without disclosing the name or identity of their children. ERC was satisfied with the voluntary participation, maintenance of the rights of the participants and confidential handling of personal information by the attending hospital physicians and has approved this consent procedure.

\section{Results}

Foster children were more likely to be infants (6 - 11 months) and $43 \%$ of them were male. Maternal illiteracy rate $(52 \%$ vs. $35 \% ; \mathrm{p}<0.001)$ was higher among foster children compared to non-foster children. Median age of the child's mother was 25 years and significant higher proportion of mothers with a foster child aged more than the median age ( $74 \%$ vs. $40 \% ; \mathrm{p}<0.001)$. Proportion of non-breast fed children $(96 \%$ vs. $14 \%$; $p<0.001)$ was higher among foster children. Most of the presenting features such as abdominal pain, vomiting, fever, duration of diarrhea ( $<24$ hours) were identically observed among both the groups except higher proportion of foster children suffered from some or severe dehydration $(60 \%$ vs. $47 \% ; p=0.001)$, duration of hospitalization $(>24$ hours) $(60 \%$ vs. $47 \% ; p=0.001)$, and received intravenous saline $(12 \%$ vs. $5 \% ; p=0.002)$. They also did not receive vitamin A capsule more frequently ( $76 \%$ vs. $60 \%$; $\mathrm{p}<0.001)$. On the other hand, they were more likely to be stunted $(64 \%$ vs. $39 \%$; $<<0.001)$, underweight $(71 \%$ vs. $45 \% ; \mathrm{p}<0.001)$ but proportion of wasting was equally distributed among both the groups (Table 1). Considering etiology of diarrhea, isolation rate of Shig-

Table 1. Socio-demographic, clinical and host characteristics of foster children.

\begin{tabular}{|c|c|c|c|c|}
\hline Variables & $\begin{array}{l}\text { Foster children } \\
n=208(\%)\end{array}$ & $\begin{array}{c}\text { Non-foster children } \\
n=624(\%)\end{array}$ & Unadjusted OR (95\% CI) & $\mathrm{p}$ value \\
\hline Age (6 - 11 months) & $184(89)$ & $400(64)$ & $4.29(2.67,6.96)$ & $<0.001$ \\
\hline Maternal illiteracy & $108(52)$ & $218(35)$ & $2.01(1.45,2.80)$ & $<0.001$ \\
\hline Maternal age ( $>$ median 25 years) & $153(74)$ & $250(40)$ & $4.16(2.90,5.98)$ & $<0.001$ \\
\hline Slum area & $20(10)$ & $50(8)$ & $1.22(0.68,2.17)$ & 0.564 \\
\hline Monthly income (>5000 tk) & $95(46)$ & $318(51)$ & $0.81(0.58,1.12)$ & 0.214 \\
\hline \multicolumn{5}{|l|}{ Wealth index } \\
\hline Poor & $28(15)$ & $105(19)$ & $0.79(0.49,1.28)$ & 0.374 \\
\hline Lower middle & $33(18)$ & $106(19)$ & $0.95(0.61,1.50)$ & 0.920 \\
\hline Upper middle & $32(18)$ & $109(19)$ & $0.89(0.56,1.40)$ & 0.671 \\
\hline Rich & $43(24)$ & $139(25)$ & $0.94(0.63,1.42)$ & 0.848 \\
\hline Use non-sanitary toilet & $74(36)$ & $241(39)$ & $0.88(0.62,1.23)$ & 0.482 \\
\hline One $(<5$ years $)$ child currently in the family after fostering & $182(88)$ & $468(75)$ & $2.33(1.46,3.75)$ & $<0.001$ \\
\hline Non-breastfed & $190(96)$ & $85(14)$ & $171.48(74.93,412.61)$ & $<0.001$ \\
\hline History of measles in last 6 months & $8(4)$ & $29(5)$ & $0.82(0.34,1.91)$ & 0.770 \\
\hline Not received vitamin A within last 12 months & $158(76)$ & $374(60)$ & $2.11(1.46,3.06)$ & $<0.001$ \\
\hline Dehydrating diarrhea (some or severe dehydration) & $122(60)$ & $286(47)$ & $1.71(1.22,2.39)$ & 0.001 \\
\hline Abdominal pain & $35(17)$ & $93(15)$ & $1.16(0.74,1.80)$ & 0.579 \\
\hline Vomiting & $148(71)$ & $453(73)$ & $0.93(0.64,1.33)$ & 0.730 \\
\hline Fever $\left(37.6^{\circ} \mathrm{C}\right)$ & $19(9)$ & $55(9)$ & $1.04(0.58,1.85)$ & 1.000 \\
\hline Duration of hospital stay ( $>24$ hours) & $122(60)$ & $286(47)$ & $1.71(1.22,2.39)$ & 0.001 \\
\hline Use of antimicrobials before coming to the hospital & $127(61)$ & $397(64)$ & $0.90(0.64,1.25)$ & 0.561 \\
\hline Use of intravenous saline & $24(12)$ & $32(5)$ & $2.41(1.34,3.34)$ & 0.002 \\
\hline Stunting (height-for-age z-score $<-2.00 \mathrm{SD}$ ) & $134(64)$ & 241(39) & $2.88(2.05,4.04)$ & $<0.001$ \\
\hline Underweight (weight-for-age z-score $<-2.00 \mathrm{SD}$ ) & $148(71)$ & $283(45)$ & $2.97(2.09,4.23)$ & $<0.001$ \\
\hline Wasting (weight-for-height z-score $<-2.00 \mathrm{SD}$ ) & $73(35)$ & $173(28)$ & $1.41(0.99,2.00)$ & 0.053 \\
\hline
\end{tabular}


ella, Salmonella and Vibrio cholerae were similar; however, proportion of rotavirus diarrhea ( $26 \%$ vs. $43 \%$; p < 0.001 ) was significantly lower among foster children (Table 2).

In multivariate analysis (backward stepwise), foster children were two times more likely to be stunted and 194 times more likely to be non-breastfed compared to non-foster children. On the other hand, infants aged 6 11 months were 8 times more likely to be fostered compared to older children and probability of fostering a child was 7 times higher among mothers aged more than 25 years (Table 3 ).

\section{Discussion}

The orhodox view from socio-cultural perspectives dictates that female children are more likely to become foster; biological parents who give their children to others, consider the female child as burden and the child is often neglected in the family of biological parents. In the present study, higher proportion of infants as foster child is one of the interesting findings in our analyses which might be due to lack of interest to be foster parents of older children. This phenomenon may be attributed to the inability of providing exclusive breastfeeding for first 6 months by the foster mothers, which has also been supported by an earlier study [2].

Lack of formal schooling of mother is one of the most important predictors for optimal infant and child care including their feeding and health care seeking behaviors [22]. It might happen that proportion of fostering would be similar irrespective of socio-economic status. However, foster children from the lower economic class might attend the hospital triage more often compared to

Table 2. Distribution of pathogens among foster children.

\begin{tabular}{cccccc}
\hline Variables & $\begin{array}{c}\text { Foster } \\
\text { children } \\
\mathrm{n}=208(\%)\end{array}$ & $\begin{array}{c}\text { Non-foster } \\
\text { children }\end{array}=624(\%)$ & $\begin{array}{c}\text { Unadjusted OR } \\
(95 \% \mathrm{CI})\end{array}$ & $\mathrm{p}$ value \\
\hline Vibrio cholerae & $18(9)$ & $40(6)$ & $1.38(0.74,2.55)$ & 0.345 \\
Rotavirus & $54(26)$ & $267(43)$ & $0.47(0.33,0.68)$ & $<0.001$ \\
Shigella & $19(9)$ & $41(7)$ & $1.43(0.78,2.61)$ & 0.279 \\
Salmonella & $4(2)$ & $6(1)$ & $2.02(0.47,8.16)$ & 0.278 \\
\hline
\end{tabular}

Table 3. Backward stepwise multivariate analysis to determine factors associated with foster children.

\begin{tabular}{ccc}
\hline Variables & Adjusted OR $(95 \% \mathrm{CI})$ & $\mathrm{p}$ value \\
\hline Age (6 - 11 months) & $7.57(3.70,15.50)$ & $<0.001$ \\
Maternal age (>25 years) & $7.27(3.96,13.33)$ & $<0.001$ \\
Non-breastfed & $194.04(82.25,457.76)$ & $<0.001$ \\
Stunting & $2.38(1.31,4.32)$ & 0.004 \\
\hline
\end{tabular}

well-off families [7]. This hypothesis might be supported by higher maternal illiteracy rate among foster mothers from lower economic class. In other words, higher maternal literacy rate among urban families with better socio-economic status might seek care from private practitioners without attending the hospital.

Higher proportion of underweight and stunted foster children can be explained by the association of higher proportion of maternal illiteracy with higher proportion of malnourished foster children [23]. Several underlying factors might predict this very important observation. Firstly, absence or lack of exclusive breastfeeding [24], which is the most important element to bolster immunity and curve infection in order to improve feeding practice, child health and development in young infancy $[25,26]$. Potential immune-compromised condition of foster children due to inadequate breast feeding led them to experience a number of morbid conditions during infancy period such as diarrhea and pneumonia. This might be supported by lower rate of vitamin A consumption which is one of the major components for development of well functioning immune system [27]. On the other hand, there may be lack of adequate knowledge of balanced diet or in poor fostering family; the child may not consume appropriate or balanced diet as complementary feeding which is again essential for late infancy [22]. Moreover, lack of appropriate social bondage and negligence might be the other factors which make them depressed compared to their counterpart [2,5]. We observed that median maternal age of foster child was 25 years, which may result from failure to become biological mother after marriage, and/or due to a lack of insight feelings of motherhood.

Foster children attending the hospital with diarrhea were more often dehydrated, needed more intravenous fluid for initial management of dehydration and stay longer period in the hospital. All these could be concurrence of malnutrition and altered immune status [23]. On the other hand, proportion of rotaviral diarrhea was lower among foster children. It has already been studied that well-nourished children are more prone to rotavirus infection than malnourished children due to availability of more binding site in the intestinal brush border [28-30]. Being malnourished, the virus cannot bind properly with the lining epithelium to manifest diarrhea because of disruption of the lining epithelial cells in the small intestine [31]. However, other etiologies such as Shigella, Salmonella or Vibrio cholerae were similar among foster and non-foster children although, malnourished children are often infected with these pathogens [31].

\section{Limitation}

This study was conducted among children attending a 
large diarrheal disease health facility, and may not be representative of the general population. However, the hospital provides cost-free treatment and it is accessible by all people, irrespective of their socioeconomic or other status. Strengths of the study include measured height and weight, using a large, systematic sample and unbiased sampling of the surveillance system and high quality laboratory performance for detection of pathogens.

\section{Conclusion}

The study findings demonstrate socio-demographic differences and health problems of foster children compared to non-foster. To date, no national survey has been conducted in Bangladesh to estimate the prevalence of fostering and to assess the health and nutritional status of foster children, and therefore it has paramount importance to conduct such a survey in different sites to acknowledge or rebut our observation as well as to develop effective programmes for improving their health and nutrition.

\section{Acknowledgements}

Hospital surveillance was funded by icddr,b and the Government of the People's Republic of Bangladesh through IHP-HNPRP. icddr,b acknowledges with gratitude the commitment of the Government of the People's Republic of Bangladesh to icddr,b's research efforts. icddr,b also gratefully acknowledges the following donors who provided unrestricted support to its research efforts during the project's life: Australian Agency for International Development (AusAID), Government of the People's Republic of Bangladesh, Canadian International Development Agency (CIDA), Embassy of the Kingdom of the Netherlands (EKN), Swedish International Development Cooperation Agency (Sida), Swiss Agency for Development and Cooperation (SDC), and Department for International Development, UK (DFID).

\section{REFERENCES}

[1] L. K. Leslie, J. Landsverk, R. Ezzet-Lofstrom, J. M. Tschann, D. J. Slymen and A. F. Garland, "Children in Foster Care: Factors Influencing Outpatient Mental Health Service Use," Child Abuse \& Neglect, Vol. 24, No. 4, 2000, pp. 465-476.

[2] J. I. Takayama, E. Wolfe and K. P. Coulter, "Relationship between Reason for Placement and Medical Findings among Children in Foster Care," Pediatrics, Vol. 101, No. 2, 1998, pp. 201-207. doi:10.1542/peds.101.2.201

[3] L. K. Leslie, J. N. Gordon, L. Meneken, K. Premji, K. L. Michelmore and W. Ganger, "The Physical, Developmental, and Mental Health Needs of Young Children in Child Welfare by Initial Placement Type," Journal of
Developmental and Behavioral Pediatrics, Vol. 26, No. 3, 2005, pp. 177-185.

[4] S. M. Horwitz, P. Owens and M. D. Simms, "Specialized Assessments for Children in Foster Care," Pediatrics, Vol. 106, No. 1, 2000, pp. 59-66.

[5] R. L. Hansen, F. L. Mawjee, K. Barton, M. B. Metcalf and N. R. Joye, "Comparing the Health Status of LowIncome Children in and out of Foster Care," Child Welfare, Vol. 83, No. 4, 2004, pp. 367-380.

[6] M. M. Garwood and W. Close, "Identifying the Psychological Needs of Foster Children," Child Psychiatry and Human Development, Vol. 32, No. 2, 2001, pp. 125-135. doi:10.1023/A:1012246723182

[7] N. R. Sarkar, K. B. Biswas, U. H. Khatun and A. K. Datta, "Characteristics of Young Foster Children in the Urban Slums of Bangladesh," Acta Paediatrica, Vol. 92, No. 7, 2003, pp. 839-842.

doi:10.1111/j.1651-2227.2003.tb02543.x

[8] E. L. Schor, "The Foster Care System and Health Status of Foster Children," Pediatrics, Vol. 69, No. 5, 1982, pp. 521-528.

[9] M. I. Benedict, S. Zuravin, M. Somerfield and D. Brandt, "The Reported Health and Functioning of Children Maltreated While in Family Foster Care," Child Abuse \& Neglect, Vol. 20, No. 7, 1996, pp. 561-571.

[10] M. I. Benedict, S. Zuravin, D. Brandt and H. Abbey, "Types and Frequency of Child Maltreatment by Family Foster Care Providers in an Urban Population," Child Abuse \& Neglect, Vol. 18, No. 7, 1994, pp. 577-585.

[11] G. F. Hobbs, C. J. Hobbs and J. M. Wynne, "Abuse of Children in Foster and Residential Care," Child Abuse \& Neglect, Vol. 23, No. 12, 1999, pp. 1239-1252.

[12] N. Halfon, A. Mendonca and G. Berkowitz, "Health Status of Children in Foster Care. The Experience of the Center for the Vulnerable Child," Archives of Pediatrics \& Adolescent Medicine, Vol. 149, No. 4, 1995, pp. 386392. doi:10.1001/archpedi.1995.02170160040006

[13] D. M. Rubin, A. L. O'Reilly, X. Luan and A. R. Localio, "The Impact of Placement Stability on Behavioral WellBeing for Children in Foster Care," Pediatrics, Vol. 119, No. 2, 2007, pp. 336-344.

[14] S. M. Horwitz, M. D. Simms and R. Farrington, "Impact of Developmental Problems on Young Children's Exits from Foster Care," Journal of Developmental \& Behavioral Pediatrics, Vol. 15, No. 2, 1994, pp. 105-110. doi:10.1097/00004703-199404000-00007

[15] R. Chernoff, T. Combs-Orme, C. Risley-Curtiss and A. Heisler, "Assessing the Health Status of Children Entering Foster Care," Pediatrics, Vol. 93, No. 4, 1994, pp. 594-601.

[16] J. I. Takayama, A. B. Bergman and F. A. Connell, "Children in Foster Care in the State of Washington. Health Care Utilization and Expenditures," Journal of the American Medical Association, Vol. 271, No. 23, 1994, pp. 1850-1855. doi:10.1001/jama.1994.03510470054034

[17] S. Kools and C. Kennedy, "Foster Child Health and Development: Implications for Primary Care," Pediatric Nursing, Vol. 29, No. 1, 2003, pp. 39-41, 44-46. 
[18] G. O. Gonzalvo, "Social Characteristics and Health Status of Children Entering Foster Care Centers," Anales Espanoles de Pediatria, Vol. 50, No. 2, 1999, pp. 151-155.

[19] K. Pears and P. A. Fisher, "Developmental, Cognitive, and Neuropsychological Functioning in Preschool-Aged Foster Children: Associations with Prior Maltreatment and Placement History," Journal of Developmental and Behavioral Pediatrics, Vol. 26, No. 2, 2005, pp. 112-122.

[20] World Health Organization, "Programme for control of diarrheal disease. In manual for laboratory investigation of acute enteric infections," World Health Organization, Geneva, 1987, pp. 9-20.

[21] M. Rahman, K. De Leener, T. Goegebuer, E. Wollants, I. Van der Donck, L. Van Hoovels and M. Van Ranst, "Genetic Characterization of a Novel, Naturally Occurring Recombinant Human g6p[6] Rotavirus," Journal of Clinical Microbiology, Vol. 41, No. 5, 2003, pp. 20882095. doi:10.1128/JCM.41.5.2088-2095.2003

[22] S. K. Roy, G. J. Fuchs, Z. Mahmud, G. Ara, S. Islam, S. Shafique, S. S. Akter and B. Chakraborty, "Intensive Nutrition Education with or without Supplementary Feeding Improves the Nutritional Status of Moderately-Malnourished Children in Bangladesh," Journal of Health, Рориlation, and Nutrition, Vol. 23, No. 4, 2005, pp. 320-330.

[23] M. J. Chisti, M. I. Hossain, M. A. Malek, A. S. Faruque, T. Ahmed and M. A. Salam, "Characteristics of Severely Malnourished Under-Five Children Hospitalized with Diarrhoea, and Their Policy Implications," Acta Paediatrica, Vol. 96, No. 5, 2007, pp. 693-696.

[24] S. K. Dey, M. J. Chisti, S. K. Das, C. K. Shaha, F. Ferdous, F. D. Farzana, S. Ahmed, M. A. Malek, A. S. Faruque, T. Ahmed and M. A. Salam, "Characteristics of Diarrheal Illnesses in Non-Breast Fed Infants Attending a Large Urban Diarrheal Disease Hospital in Bangladesh," PLoS One, Vol. 8, No. 3, 2013, Article ID: e58228. doi:10.1371/journal.pone.0058228

[25] A. Varalda, A. Coscia, P. Di Nicola, G. Sabatino, I. Rov- elli, F. Giuliani, A. Soldi, C. Perathoner and E. Bertino, "Medication and Breastfeeding," Journal of Biological Regulators \& Homeostatic Agents, Vol. 26, No. 3, 2012, pp. 1-4.

[26] E. Bertino, A. Varalda, P. Di Nicola, A. Coscia, L. Occhi, L. Vagliano, A. Soldi and C. Perathoner, "Drugs and Breastfeeding: Instructions for Use," Journal of Maternal-Fetal and Neonatal Medicine, Vol. 25, No. 4, 2012, pp. 78-80. doi:10.3109/14767058.2012.715034

[27] S. Chen, Y. Yang, X. Yan, J. Chen, H. Yu and W. Wang, "Influence of Vitamin a Status on the Antiviral Immunity of Children with Hand, Foot and Mouth Disease," Clinical Nutrition, Vol. 31, No. 4, 2011, pp. 543-548.

[28] D. Mondal, J. Minak, M. Alam, Y. Liu, J. Dai, P. Korpe, L. Liu, R. Haque and W. A. Petri Jr., "Contribution of Enteric Infection, Altered Intestinal Barrier Function, and Maternal Malnutrition to Infant Malnutrition in Bangladesh," Clinical Infectious Diseases, Vol. 54, No. 2, 2012, pp. 185-192.

[29] S. K. Das, M. J. Chisti, S. Huq, M. A. Malek, M. A. Salam, T. Ahmed and A. S. G. Faruque, "Etiology of Diarrhea among Severely Malnourished Infants and Young Children: Observation of Urban-Rural Differences over One Decade in Bangladesh," Food and Nutrition Sciences, Vol. 4, No. 3, 2013, pp. 233-239. doi: $10.4236 /$ fns. 2013.43031

[30] N. Dewan, A. S. Faruque and G. J. Fuchs, "Nutritional Status and Diarrhoeal Pathogen in Hospitalized Children in Bangladesh," Acta Paediatrica, Vol. 87, No. 6, 1998, pp. 627-630. doi:10.1111/j.1651-2227.1998.tb01520.x

[31] J. M. Rhoads, B. A. Corl, R. Harrell, X. Niu, L. Gatlin, O. Phillips, A. Blikslager, A. Moeser, G. Wu and J. Odle, "Intestinal Ribosomal p70(s6k) Signaling Is Increased in Piglet Rotavirus Enteritis," American Journal of Physiology_Gastrointestinal and Liver Physiology, Vol. 292, No. 3, 2007, pp. G913-G922. 